\title{
EM LETRAS E RITMOS: VISÕES DE ESCOLA, EDUCAC̄̃̃ E TRABALHO NO SAMBA BRASILEIRO (1930-1950)
}

\author{
MARIA ANGELA BORGES SALVADORI ${ }^{*}$ \\ ORCID: https://orcid.org/0000-0001-5075-014X
}

RESUMO: Este artigo analisa o modo como questões ligadas ao analfabetismo, escola, educação e experiência foram tratadas em canções compostas por sambistas brasileiros que se autodenominavam "malandros". Dialogando com a história social inglesa, particularmente com os trabalhos de E. P. Thompson, considera que este cancioneiro constitui fonte histórica que permite o acesso a formas de pensar e sentir dos grupos populares quanto à escola e à educação, especialmente entre os anos 1930 e 1950, período em que esses sambas alcançaram sucesso por meio do rádio. Conclui que essas composições, mesmo tematizando sujeitos ou situações singulares, foram exercícios sonoros de crítica social e educação política, com a constância de certas tópicas: denúncia das desigualdades educacionais e escolares e do preconceito contra o analfabeto, conflito entre cultura letrada e cultura popular e, por fim, uma postura anti-intelectualista que desdenhava dos saberes escolares vistos como pouco úteis diante das urgências da vida cotidiana.

Palavras chave: História da Educação; Samba; Radiodifusão; Cultura Popular; Música Popular Brasileira.

\section{LYRICS AND RHYTHMS: VIEWS OF SCHOOL, EDUCATION AND WORK IN BRAZILIAN SAMBA (1930-1950)}

ABSTRACT: This article analyzes how illiteracy, school, education and experience were treated in songs composed by Brazilian samba artists who called themselves malandros (astute individuals capable of circumventing rules and situations that might force them into submission). Dialoging with English social history, particularly with E. P. Thompson's work, the article considers this songbook a historical source of the thoughts and feelings of the popular groups about school and education, especially between the 1930 s and 1950s, when these sambas became popular through the radio. It concludes that, although these compositions addressed singular situations or subjects, they were sound exercises of social criticism and political

\footnotetext{
${ }^{1}$ Universidade de São Paulo, São Paulo SP, Brasil

"Graduada e mestre em História pelo Instituto de Filosofia e Ciências Humanas da Unicamp. Doutora em Educação pela Faculdade de Educação da Unicamp. Docente da Faculdade de Educação da Universidade de São Paulo (USP) na área de História da Educação. Membro do NIEPHE - Núcleo Interdisciplinar de Estudos e Pesquisas em História da Educação. Email:<mabsalvadori@usp.br >.
} 
education, thanks to the constant presence of certain topics: denunciation of educational and school inequalities and of prejudice against the illiterate, conflict between literate and popular culture and, finally, an antiintellectualist stance that disdained school knowledge, seen as useless in the face of the urgencies of everyday life.

Keywords: History of Education; Samba; Broadcasting; Popular Culture; Brazilian Popular Music.

\section{INTRODUÇÃO: EDUCAÇÃO, SAMBA E TRABALHO}

"Pá escrevê uma boa letra de samba, sentida... humana... a gente tem de sê, em primeiro lugal, narfabeto". Assim falava Adoniram Barbosa em um dos diálogos de História das Malocas, sucesso de audiência da Rádio Record de São Paulo nos anos $1950 .{ }^{1}$ Tratava-se de um programa humorístico encenado por Oswaldo Moles (1913-1967), seu idealizador, e pelo próprio Adoniran (19101982), além de outros radioatores que, em conversas carregadas da linguagem das ruas, contavam as mazelas e as alegrias dos pobres na capital paulista (ROCHA, 2002). Adoniran foi também compositor de sambas que enalteciam a malandragem e exaltavam as virtudes daqueles que, por motivos vários, estiveram à margem do mundo regular do trabalho e da educação formal escolar sem, todavia, deixar de refletir sobre os significados sociais desta exclusão. O programa citado teve inspiração em sua famosa composição Saudosa Maloca, gravada primeiro em 1951 pelo próprio compositor e, depois, em 1955, pelo conjunto Demônios da Garoa, quando alcançou grande popularidade. Parte significativa dos sucessos de Adoniram naquele período apresenta uma outra visão sobre a cidade de São Paulo, distinta das representações de progresso que, às voltas do Quarto Centenário, povoavam os programas de rádio e as páginas da imprensa. Sua fala sugere também uma relação ambígua entre linguagem, educação e escola na medida em que, distante do aprendizado formal da língua e mais próxima da oralidade dos trabalhadores e das ruas, compreende esta distância como valor e qualidade estética ao mesmo tempo em que expõe facetas da desigualdade social e educacional.

Este texto se debruça, exatamente, sobre um conjunto de canções compostas por sambistas que se autodenominavam "malandros" e sobre o modo como temas tais como analfabetismo, escola, educação, formação e experiência aparecem nessas canções. Estes sambistas conquistaram maior notoriedade a partir dos anos 1930, seja porque o rádio foi um caminho para a divulgação de 
suas músicas - também para o sustento financeiro -, seja porque o contexto varguista de culto e devoção moral ao trabalho lhes propiciou inspiração para a retomada de antigas tradições populares que questionavam as regras do "batente" regular, especialmente a submissão ao patrão e aos ritmos da fábrica. Sobrevivendo via rádio, vendendo e/ou gravando músicas, tais compositores garantiam alguma autonomia, ainda que não enriquecessem, e se mantiveram alheios à introjeção do tempo como valor moral, seu uso parcimonioso e controlado, orientado por interesses econômicos (THOMPSON, 1998). O rádio lhes proporcionou, ainda, uma escuta que, de alguma maneira, se identificava com o que era veiculado nas melodias, alinhamento corroborado tanto pelo interesse da indústria fonográfica quanto pela audiência radiofônica. Em trabalho anterior, tentei demonstrar que muitas composições malandras podem ser vistas como portadoras de tradições de luta por liberdade aprendidas desde os tempos da escravidão. A pecha da vadiagem que recaía sobre esse grupo de trabalhadores e sobre seus "ascendentes", assim julgados por parte do senso comum, pelos discursos jurídico e médico e pelo Estado, escondia aquilo que essas falas musicais mostravam: eles trabalhavam mas buscavam se afastar da presença vigilante do patrão e das regras do trabalho formal; procuravam uma vida com alguma independência, resgatando a ideia do "viver sobre si", um dos sentidos da liberdade engendrados ainda nos tempos da escravidão. As acusações de vadiagem das quais foram vítimas constituíam-se antes em esforços de controle e repressão por parte dos grupos sociais dominantes, temerosos da perda dos privilégios que a escravidão lhes garantia e ávidos por novas estratégias de disciplinarização social (SALVADORI, 1990).

O objetivo aqui é identificar e analisar o tratamento de temáticas relacionadas à educação e à escola nas composições deste grupo que, via de regra, exaltava a malandragem e defendia a autonomia como caminho para a liberdade. As composições aparecem, portanto, como portadoras de outras vozes e de uma visão crítica da sociedade - também do passado dessa sociedade - em que foram compostas. Suas letras, muito próximas ao vocabulário das ruas, permitem dialogar com as conclusões às quais Bakhtin chegou ao estudar a cultura popular da idade média e do renascimento a partir das obras de Rabelais, considerando os processos de interação verbal e a linguagem como práticas sociais. O intelectual russo demonstrou que é necessário pensar a linguagem como prática sóciohistórica na qual a fala de um sujeito só pode ser compreendida em 
termos de seu sentido em relação ao outro e no entrecruzamento das vozes que a constituem. Além disso, conferindo especial atenção às festas populares do medievo, apontou o riso e o humor como ferramentas jocosas de crítica social e como possibilidade de alguma liberdade, já que o cômico questiona as estruturas sociais, desigualdades e submissões sustentadas pelo temor (BAKHTIN, 1987). As composições aqui analisadas, como se verá à frente, são marcadas por uma linguagem de requintada ironia e jocosidade. Ainda que tratem de temas trágicos, ganham leveza pelo uso desses recursos que, entendo, foram apropriados por esses compositores a partir da linguagem em que se constituíram como sujeitos e que compartilhavam com os próximos em condição: "só os iguais riem entre si" (HERZEN apud BAKHTIN, 1987, p. 80).

Em perspectiva mais próxima no tempo e no espaço, Silva (1999) mostrou que, nos primórdios do rádio, quando a profissionalização era ainda tímida e o improviso vicejava, os anúncios radiofônicos reproduziam o vocabulário das ruas, particularmente o dos antigos mascates que com seus cantos e falas procuravam fregueses na cidade. Menezes (2007) investigou os vínculos sonoros entre o rádio e seus ouvintes na capital paulistana e, embora com uma periodização mais contemporânea, sustenta que a escuta radiofônica é carregada de afetos e conexões construídos historicamente a partir de realidades compartilhadas. Tais reflexões autorizam a hipótese de que os sambas e as marchas compostos por esses sujeitos que se autodefiniam como malandros, repletos de ironia, humor e chiste, podem ser tomados como fontes históricas que, a um só tempo, contavam sobre as agruras do trabalho, realizavam o elogio da vadiagem e propagavam pelo rádio uma crítica social compartilhada pelos ouvintes ou, ao menos, por parte dos ouvintes que defendia um rádio mais popular e voltado ao lazer. ${ }^{2}$

\section{HISTÓRIAS SOCIAIS DA MÚSICA}

Uma mirada sobre as pesquisas que se valem da música como fonte indica que, na área da história da educação, prevalecem estudos ligados à história de seu ensino (QUEIROZ, 2012), às trajetórias e formação de professores de música (ESPERIDIÃO, 2012) e sobre práticas tais como o canto orfeônico (MONTEIRO, SOUZA, 2003; CONTIER, 1998). Há também trabalhos sobre as propostas educativas dos pioneiros do rádio (GILLIOLI, 2008) e acerca de programas radiofônicos de caráter educativo (COELHO, 2017). No 
campo mais ampliado da história, não poucos historiadores têm feito da música popular brasileira seu objeto e fonte de pesquisa. Em geral, duas abordagens são mais frequentes: ora a música, a música popular em particular, é caminho para o acesso à história das cidades e do urbanismo, da radiodifusão, do trabalho, do carnaval, dos movimentos sociais e das lutas políticas, entre tantos outros temas, ora é valorizada como recurso didático em pesquisas dedicadas ao ensino de história, tendência que contempla também um número significativo de estudos. Em comum, uns e outros destacam o potencial desse tipo de documentação no que se refere ao mapeamento de experiências ligadas aos grupos subalternos e/ou dissidentes.

O uso de repertórios da música popular brasileira, de diferentes períodos, como fonte histórica tornou-se mais comum a partir dos anos 1980, movimento resultante das renovações da historiografia e do lugar privilegiado que concederam a diferentes tradições populares. Foi a partir daí que os estudos históricos sobre música se distanciaram de abordagens mais folclóricas e eruditas e passaram a vê-la como vestígio significativo para o acesso, por exemplo, à cultura e ao cotidiano de grupos populares. Nessa direção, o clássico livro de Eric Hobsbawm, História Social do Jazz (1990), publicado pela primeira vez sob pseudônimo de Francis Newton no início da década de 1960, é sempre uma inspiração. Na obra, de maneira inovadora, o jazz foi analisado em suas históricas origens sociais, definido como um tipo de música ligada à experiência dos negros no sul dos Estados Unidos, uma mescla de ritmos africanos e europeus, uma música dos trabalhadores pobres, nascida na América no limiar do século XX. Hobsbawm afirma que o jazz é exemplo de um tipo de cultura popular que sobreviveu aos processos rápidos de mudanças da primeira metade dos Novecentos, transformando-se ele também ao longo do tempo, mas sem sucumbir plenamente aos ditames da indústria cultural. É uma música popular cujas raízes se vinculam ao universo das tradições orais, um ritmo visto como inferior e marginal, tal como ocorreu, no Brasil, com o samba (JOST, 2015). Ao abordar historicamente o jazz, ele localiza seu aparecimento entre os grupos de trabalhadores pobres do sul dos EUA, negros e brancos.

Boa parte do que Hobsbawm afirma sobre o jazz parece ajustar-se ao samba brasileiro, ligado também a grupos marginalizados, com escalas musicais marcadas por sons e ritmos de matriz africana e modos de tocar sempre pessoais e mutantes; samba e jazz são "música de executantes" uma vez que as pessoas participam ativamente: umas tocam, outras cantam, muitas acompanham com pés, mãos e voz 
(HOBSBAWM, 1990, p. 45). Ambos compartilham uma história ligada à escravização de africanos e afrodescendentes e aos modos como criaram formas de resistência e espaços de alguma liberdade. O improviso, individual ou coletivo, faz parte desses ritmos avaliados pelas elites culturais de então como "gritos" (no caso de jazz) ou barbárie (no caso do samba). ${ }^{3}$ Em comum, ainda, o fato de que nasceram em um período marcado pela intensificação dos processos de urbanização e de aparecimento de formas de lazer e entretenimento destinadas às classes trabalhadoras; constituíram-se em uma música de resistência e protesto frente ao empobrecimento crescente, à exclusão social, ao preconceito de cor e de classe; passaram por um processo de apropriação por parte do Estado e massificação cultural, mas mantiveram características que lhes eram próprias desde os primórdios; de expressões da "baixa cultura", foram alçados a símbolos nacionais e valorizados pela indústria fonográfica emergente. Considerando a pertinência dessas similitudes, é possível pensar nos sambas, os sambas malandros em especial, como fontes que contam a história da música, de seus compositores e, ainda, de seu público. São, por assim dizer, histórias sonoras que carregam os significados atribuídos às experiências sociais específicas de um grupo.

Essa identificação entre o samba e os grupos subalternos é destacada também por José Geraldo Vinci de Moraes (2000) ao notar que a canção popular é mais facilmente acessada por pessoas menos escolarizadas, diferentemente de outras formas de arte, de música em particular. Muitos trabalhos podem ser citados aqui como exemplos de pesquisas que entrelaçam história e música (CONTIER, 1991; BRITO, 1986; NAVES, 2015, WISNIK, 1989, CUNHA, 2015). Alguns se aproximam mais diretamente da lente escolhida neste artigo, como é o caso de textos publicados por Marcos Napolitano, historiador que tem se debruçado sobre esse tipo de fonte sonora, versando em especial sobre o período da ditadura militar e o papel das canções de protesto. Napolitano discute essa categoria documental e as mudanças pelas quais sua abordagem foi passando ao longo da historiografia, superando o estudo de movimentos e gêneros específicos - Tropicália, Bossa Nova, Samba, por exemplo - e o tema da indústria cultural para alcançar um outro tipo de uso nas análises historiográficas de matriz sociocultural. Em um de seus trabalhos, explora o que denomina como "canções dos anos de chumbo", entre 1969 e 1974, e "canções da abertura”, entre 1975 e 1982, referindo-se a ambas como tendências que buscavam "a realização de uma educação poética e sentimental da cidadania e do consumidor cultural que se supunha 
crítico ao regime militar (...)" (NAPOLITANO, 2010, p. 396, grifos meus). Examinando as letras e ritmos dessas canções, afirma que a música engajada daqueles anos, compartilhada com o ouvinte, ajudava "a construir um sentido para a experiência social da resistência ao regime militar" (NAPOLITANO, 2010, p. 390).

Aqui, subscrevo essa hipótese de que a música representa uma ferramenta de "educação poética e sentimental" - e também de educação política - ao mesmo tempo em que é fonte para o acesso a formas específicas de ver o mundo e contá-lo. Emprestando a visão de Antônio Cândido (2002), penso essas composições como elemento fundamental para a formação humana, tal como ele fez referindose à função social da literatura, tomada como experiência sensível e não apenas como produção cultural stricto sensu. Cândido afirma que a literatura é um instrumento de educação poderoso na medida em que nos humaniza e atua sobre nossa formação. Defende que a literatura, sempre de algum modo referenciada na realidade, possui uma função integradora e que seu caráter formativo reside num processo mais intenso que aquele que a escola pode proporcionar, se formos capazes de pensar a educação para além da configuração escolar e suas normas. Proferido pela primeira vez como uma palestra no início dos anos 1970, o texto "A literatura e a formação do homem" apresenta os debates que cercavam os estudos literários e seu ensino. Embora hoje as discussões sobre enfoques estruturais e enfoques funcionalistas, ao menos no campo da história, possam parecer já um tanto anacrônicas, o ensaio de Antônio Cândido preserva sua juventude na medida em que define o caráter formativo da literatura como rebelde, avesso ao canônico saber escolar. Por este motivo, ora ela é expulsa porque "fonte de perversão", ora acomodada na "bitola ideológica dos catecismos" (CÂNDIDO, 2002, p. 83). Destaca, ainda, que a literatura ajuda a tornar a realidade mais legível e, com exemplos do regionalismo, atribui ao leitor o papel de coparticipante, alguém que se reconhece naquilo que lê; ou que conhece o outro por meio daquilo que lê (CÂNDIDO, 2002, p. 92). Em outras palavras, alguém que aprende.

Creio ser possível estender esse caráter educativo da literatura também para a música, para todos os tipos de música e para a música popular, em particular para o samba, que pode mostrar-se ainda mais abrangente posto que atinge o universo tanto de escolarizados quando de não letrados. Opera-se aqui, portanto, com duas dimensões das relações entre escola, educação e sambas malandros: aquela que envolve o processo de conhecimento de si e aquela que envolve o conhecimento do mundo. 
Para investigar concepções e sensibilidades morais das pessoas comuns quanto à escola e à educação, bem como as relações entre cultura escolar e outras culturas que lhe são exteriores, este artigo se apoia nas perspectivas da história social inglesa. Entende-se que esta corrente historiográfica permite tanto compreender sentidos de formação atribuídos pelos sujeitos a sua própria experiência, mais distanciados da escola e mais aproximados do cotidiano de trabalho, moradia, vida urbana, entre outros aspectos, quanto certa postura anti-intelectualista tal como aquela que se infiltra na fala de Adoniran no início deste artigo, secundarizando a alfabetização e o domínio da norma culta da língua como condições para a composição de um bom samba.

Adotando os pressupostos da história social, examino a seguir como educação, escola e experiência se entrelaçam nessas obras musicais, apostando na hipótese de que se constituem em sonoras tradições de resistência nas quais se encontram uma visão crítica sobre a escolarização formal e a denúncia da exclusão escolar a que estavam submetidas as parcelas mais pobres da população; ao mesmo tempo, essas tradições enaltecem outros processos formativos, informais, difusos, sintetizados na oposição entre a escola regular e "escola da vida". Considera-se, ainda, que estas músicas são parte de processos de autoformação de visões de mundo e comportamentos de grupos populares, capazes de produzir solidariedades específicas.

Além da obra de Adoniran Barbosa, sambas compostos por Wilson Batista e Geraldo Pereira, entre outros, são tomados simultaneamente como fontes e objeto de estudo, numa periodização que inclui as décadas de 1930 a 1950, quando tais compositores se consagraram pelo rádio. Em comum, trajetórias marcadas pela experiência da pobreza e pela vida nos morros e/ou em bairros operários. Para além das letras, a análise incide também sobre os ritmos, especialmente sobre os contrates entre os "sambas de breque", quase dialogados, com as marcas do sujeito cantor, e as marchas, geralmente utilizadas nas canções que tratavam do universo do trabalho. Em ambos, a denúncia da exclusão, dentro e fora da escola e a percepção clara, expressa na linguagem, do lugar do excluído.

Seguimos, portanto, as sugestões de alguns pesquisadores que têm insistido numa ampliação do campo de estudos da história da educação e valorizado a perspectiva da história social para tal. No livro Edward P. Thompson, história e formação (2010), Liane Maria Bertucci, Luciano Mendes de Faria Filho e Marcus Aurélio Taborda de Oliveira defendem as potencialidades do diálogo com o historiador inglês, particularmente a partir da forma como operou com os conceitos 
de cultura e experiência. Dentre outras contribuições possíveis, os autores destacam dois caminhos: primeiro, "a possibilidade de pensar a formação além dos estreitos limites da escola” (BERTUCCI, FARIA FILHO, OLIVEIRA, 2010, p. 11), no sentido da autoformação, entendida como processo no qual os sujeitos se educam a partir de sua experiência. E, ainda, trabalhando com o conceito de escolarização, Bertucci, Faria Filho e Oliveira (op. cit.) bem como Vidal e Biccas (2008) sinalizam para a necessidade de refletir sobre os modos como diferentes grupos sociais se relacionam com a escola e com os saberes escolares, ora na tensão com outros saberes, mais populares, ora na incorporação dos valores caros à educação formal ou, ainda, numa leitura mais crítica e autônoma de tais valores. Também a pesquisadora Alessandra Schueler tem apostado nesse caminho:

\begin{abstract}
“(...) Não estamos nem de longe propondo o abandono dos estudos sobre a escola como instituição de educação, em seus moldes mais clássicos. Entretanto, é necessário avançar na proposição de novos olhares sobre o mesmo problema de pesquisa, bem como novos objetos e novas abordagens. Podemos pesquisar outras formas e práticas de ensino - aprendizagem vivenciadas fora das salas de aula, nos espaços sociais plurais, mas que também estão repletas de tensões políticas e sociais. Por exemplo, pensamos aqui no tirocínio artesanal das oficinas; no âmbito do trabalho urbano e rural; mas heterogêneas formas de relações familiares; nas práticas difusas e informais de transmissão de valores; nos meios de comunicação de massa; no teatro, nas redes e tecnologias de informação, etc., etc.” (SCHUELER, 2014, p. 21).
\end{abstract}

Inspirada por estes estudos e proposições, apresento a seguir a análise de alguns sambas compostos por este grupo que se autodenominava malandro, portador de um conjunto de astúcias e saberes capazes de permitir uma vida que, embora no "fio da navalha", lhe garantiu sustento e reconhecimento social.

\title{
OLHARES CRÍTICOS SOBRE ESCOLA, EDUCAÇÃO E TRABALHO EM SAMBAS MALANDROS
}

O compositor Wilson Batista (1913-1968) consagrou-se pelo rádio em sua "era de ouro". Seus biógrafos afirmam que ele teve poucas possibilidades de estudo na infância e na juventude e que assinava o nome com dificuldade, embora as letras de samba lhe saíssem mais facilmente. Nascido na cidade de Campos, RJ, filho de um trabalhador da construção civil, sempre conviveu com o samba, a boemia e o carnaval pois sua avó tinha um rancho carnavalesco que ele frequentou desde a barriga da mãe e vários outros familiares eram músicos; vivendo 
em tal ambiente, começou a compor menino. Nem todos, entretanto, viam com bons olhos esse precoce pendor musical e patusqueiro e uma de suas tias, mais conservadora, tratou de matriculá-lo na Escola de Aprendizes Artífices do Estado do Rio de Janeiro, sediada em Campos. A tia, provavelmente, acompanhava o raciocínio do presidente Nilo Peçanha, ao criar escolas profissionais federais em 1909:

“(...) considerando que o aumento constante da população das cidades exige que se facilite às classes proletárias os meios de vencer as dificuldades sempre crescentes da luta pela existência;

Que para isso se torna necessário não só habilitar os filhos dos desfavorecidos da fortuna com o indispensável preparo técnico e intelectual, como fazê-los adquirir hábitos de trabalho profícuo que os afastará da ociosidade ignorante, escola do vício e do crime..." (BRASIL, 1909)

Wilson Batista foi matriculado no curso de marcenaria mas não se adaptou e pouco permaneceu na escola (ALZUGUIR, 2013), buscando outra sorte no Rio de Janeiro, cidade na qual chegou aos 16 anos de idade. Vender músicas foi sua primeira fonte de sustento na capital, antes de fazer sucesso no rádio com sambas de breque e marchinhas (GOMES, 1985). Ao menos duas de suas canções, Chico Brito e Bastião, tomadas aqui como exemplos da potencialidade das fontes sonoras como pistas para outras histórias da educação, denunciavam a falsa promessa redentora da escola, criticavam os processos profundamente desiguais que levavam à exclusão escolar de amplas parcelas da população - dos quais foi também vítima - e sugeriam outros modos e práticas de formação.

Lá vem o Chico Brito

Descendo o morro nas mãos do Peçanha

É mais um processo

É mais uma façanha

Chico Brito fez do baralho seu melhor esporte

É valente no morro

Dizem que fuma uma erva do Norte.

Quando menino teve na escola

Era aplicado, tinha religião

Quando jogava bola era escolhido para capitão

Mas a vida tem os seus revezes

Diz sempre o Chico defendendo teses

Se o homem nasceu bom

E bom não se conservou

A culpa é da sociedade que o transformou.

(Wilson Batista, Chico Brito, 1949) 
O samba assinala os antagonismos entre duas formas de viver. Em criança, Chico Brito frequentou a escola, seguiu uma moralidade religiosa, exerceu uma liderança vista como positiva; crescido, adotou outra conduta: o jogo, a agilidade física, a valentia, os vícios. Os versos iniciais da canção são marcados pela ambiguidade entre o sujeito que desce o morro "pelas mãos do Peçanha", ou seja, foi apanhado pelo comissário e responderá a mais um processo, e o uso da palavra "façanha" que, embora bastante utilizada pelo discurso policial à época para incriminar sujeitos acusados de vadiagem, adquire entre os iguais uma conotação positiva, dos grandes feitos, inclusive o de desafiar constantemente a polícia, face do Estado mais conhecida pelas classes populares.

Interessa ainda a argumentação de Chico Brito acerca dos reveses da vida e a hipótese que formula para explicá-los a partir da ideia de que o "homem nasce bom, mas a sociedade o transforma", máxima do filósofo iluminista Rousseau ao tratar da bondade natural do homem, atribuindo à sociedade as responsabilidades por condutas ulteriores e pela corrupção do caráter, questão que está presente tanto no Contrato Social quanto em Emílio, ambos escritos nos primeiros anos da década de 1760 (BOTO, 2012). Adotando uma postura de crítica social, como fez em tantos outros de seus sambas, Wilson Batista mesclou valores próprios a grupos populares cariocas às explicações consagradas em outros espaços, mais intelectualizados. Embora o sujeito da canção tenha frequentado a escola, esta experiência não lhe ofereceu o necessário ou o desejado - para viver; tampouco mostrou-se bem-sucedida. O que temos é um samba no qual pobreza, e mesmo delinquência, não são tratadas exclusivamente como fracasso ou escolha pessoal. O tipo de mudança e infortúnio que aparecem aqui, certamente, compunham parte da experiência dos radiouvintes, o que ajuda a entender o sucesso da canção à época de seu lançamento, em 1949. Tomando o samba como um discurso popular, Ricardo Azevedo salienta que a crítica social é um dos temas historicamente mais frequentes nesse tipo de composição e que grandes problemas sociais são tratados a partir de experiências mais pessoais ou locais (AZEVEDO, 2013). Assim, vários sambas que contam a história de um personagem podem ser ouvidos como histórias mais coletivas e, deste modo, entendidos como o compartilhamento e a reflexão acerca da realidade.

Em Bastião, marchinha de grande sucesso em 1954, Wilson Batista retoma a denúncia das desigualdades e injustiças sociais relacionando-as de modo ainda mais direto ao universo da escola e da educação: 


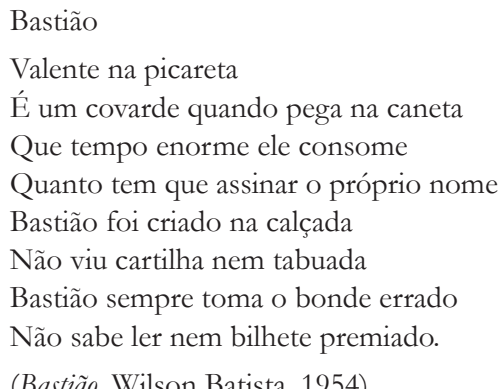

$\mathrm{Na}$ primeira letra, a falácia da escola enquanto possibilidade de ascensão social; nesta, a denúncia da exclusão, explicitada nas oposições entre força física - "valente na picareta" - e as dificuldades no trato com a caneta, as letras e as contas. A imagem reitera estereótipos acerca do trabalhador analfabeto, um "otário" que nem mesmo lê um bilhete premiado que poderia lhe tirar da vida dura e da ignorância. Bastião "não viu cartilha nem tabuada", verso que revela conhecimento sobre saberes clássicos da escola primária e, ao mesmo tempo, denuncia uma segregação por meio da oposição entre o espaço ideal da escola e o espaço da rua. Creio que seria tímido demais entender esses versos como uma crítica direta à figura do trabalhador analfabeto da construção civil. Ao personificar o problema em Bastião, o compositor certamente tratava de conjunturas e realidades sociais mais amplas, operando a crítica social por meio de sua encarnação na realidade de um sujeito. A canção sinaliza, ainda, para as dificuldades encontradas pela população analfabeta em ambientes urbanos nos quais o domínio da leitura e da escrita tem implicações no que se refere à mobilidade, sociabilidade e empregabilidade. Por fim, vale notar que Chico Brito tinha nome e sobrenome, identidade e reconhecimento, enquanto Bastião é apenas a corruptela de um nome e impossibilita a distinção de um sujeito singular.

Além das letras, também os ritmos escolhidos são repletos de significado. Chico Brito é um samba de breque, tem uma melodia que se assemelha à ginga do malandro, por sua vez atrelada à capoeiragem e às tradições de liberdade, um samba entrecortado pela fala do sujeito que se impõe. Bastião é uma marchinha, ritmo muitas vezes escolhido para canções que tematizam o trabalho e o trabalhador, marcado pela repetição das notas e por certa monotonia melódica, mais adequada à realidade do labor urbano e fabril (SALVADORI, 1990). Ambas fizeram grande sucesso no rádio, o que sugere que os ouvintes se identificavam com tais críticas e denúncias, divisavam seu cotidiano nessas composições e assim formavam uma visão de mundo. 
Outro compositor malandro, Geraldo Pereira (1918-1955), abordou em seus sambas temas associados à escola e a educação. Mineiro de Juiz de Fora, também negro, nascido em 1918, chegou ao Rio de Janeiro em 1930 e, no ano seguinte, ingressou no curso primário da Escola Pará, em Vila Isabel, posteriormente Escola Olímpia do Couto. Trabalhou inicialmente com o irmão numa venda do Morro da Mangueira e depois empregou-se em uma fábrica de vidro como soprador. Aos 18 anos, aprendeu a guiar, tirou carteira e se tornou funcionário público, dirigindo o caminhão do serviço de limpeza urbana, ao mesmo tempo em que frequentava assiduamente as rodas de samba da Mangueira (INSTITUTO CULTURAL CRAVO ALBIN, s/d). Não poucas vezes encontrou-se com Wilson Batista e em parceria com ele compôs, em 1940, o samba Acertei no Milhar, também de breque, imortalizado na voz de Moreira da Silva que, quase falado, reproduz a linguagem das ruas, contando alegremente as mudanças de vida e os planos de futuro a serem colocados em prática com a vitória no jogo:

Etelvina

Acertei no milhar!

Ganhei quinhentos contos, não vou mais trabalhar

você dê toda roupa velha aos pobres

e a mobília podemos quebrar

"Isso é pra já, vamos quebrar. Passe pra cá Pam, pam, bum"

Etelvina vai ter outra lua de mel

você vai ser madame

vai morar num grande hotel

eu vou comprar um nome não sei onde

de Marquês Morengueira de Visconde

um professor de francês mon amour

eu vou mudar seu nome pra Madame Pompadour

Até que enfim agora sou feliz

vou passear a Europa toda até Paris

e nossos filhos, oh, que inferno

eu vou pô-los num colégio interno

me telefone pro Mané do armazém

porque não quero ficar devendo nada a ninguém

e vou comprar um avião azul

para percorrer a América do Sul

mas de repente, derrepenguente

Etelvina me acordou está na hora do batente

mas de repente, derrepenguente

- Se acorda, Vargulino! Saia pela porta de trás que na frente tem gente.

Foi um sonho, minha gente!

(Acertei no Milhar, Wilson Batista e Geraldo Pereira, 1940) 
Há muito da experiência dos trabalhadores pobres nesta canção: o trabalho não leva à melhoria das condições da vida, o enriquecimento é sempre um sonho a ser alcançado apenas pela sorte e os sonhos são sempre interrompidos pelas urgências do cotidiano. Mas o samba também aponta para uma associação entre a riqueza e a possibilidade de aquisição de certos saberes: a mulher aprenderá a falar francês com um professor particular, deste modo apropriandose de uma língua associada à cultura e a padrões de comportamento europeus - a própria referência à cortesã francesa reforça esse imaginário ao mesmo tempo em que identifica os privilégios que o dinheiro pode comprar; os filhos serão colocados em um colégio interno, assim mostrando as desigualdades entre a educação dos ricos - a escola particular, o internato - e a educação dos pobres. A letra sugere também uma relação com a infância diferente por parte de famílias ricas e famílias pobres. O samba de breque, cantado como quem fala, insere a educação na crítica social que veicula.

Uma outra composição, interpretada por Adoniran no mesmo programa citado no início deste artigo, no qual atuava como o personagem Charutinho, ilustra uma vez mais essas ambíguas formas de interseção entre escola e educação:

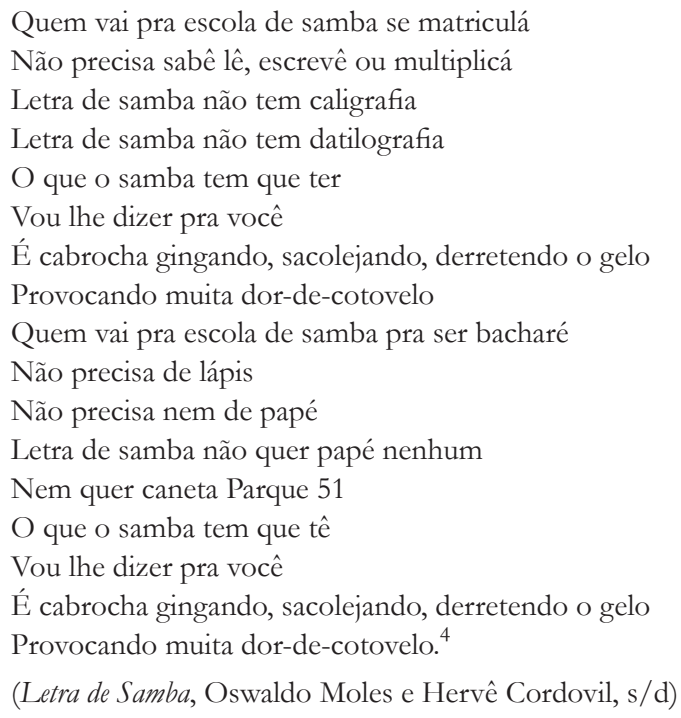

Francisco Rocha, estudioso da vida e da obra de Adoniran Barbosa, afirma que as letras que aparecem no LP Histórias das Malocas foram compostas por Oswaldo Moles, diretor do programa, e pelo maestro Hervê Cordovil (ROCHA, 2002, p. 108). Entretanto, na voz de 
Adoniran - porque a fonte sonora é também seu canto -, a composição encontra uma linguagem que se associa aos modos de falar dos pobres, confirmando o que muitos estudiosos da comunicação dizem acerca do sucesso da radiodifusão de caráter mais comercial a partir da década de 1930, visto como resultado da apropriação, por parte dos profissionais do rádio, das falas das ruas, cativando o ouvinte por semelhança e aproximação (SILVA, 1999). Importa ainda ressaltar a ambiguidade com a qual o par oralidade/escrita é tratado: a letra, por seu conteúdo e forma, repleta de "erros" de português, escancara as desigualdades educacionais, estampadas na não observância à gramática normativa da língua e reconhece a oposição entre o universo letrado e o universo popular. Todavia, título, lápis, papel e caneta, que na canção simbolizam a condição letrada, são desvalorizados frente aos saberes advindos da experiência no que se refere à "educação sentimental" necessária à produção de um bom samba. E, é claro, há uma inteligência no uso da linguagem capaz de tornar popular - e famoso e bem-sucedido - tanto os compositores quanto o cantor e o programa.

Em Não se aprende na escola, samba composto por Haroldo Barbosa (1915-1979) e gravado pela intérprete Aracy de Almeida em 1951, uma outra relação aparece, desta vez ligada aos conteúdos escolares curriculares, como se pode perceber em sua primeira estrofe e refrão:

Dom Pedro disse 'fico'
E ficou, que maravilha
Mas quem ficou com Pedro
Foi a Dona Domitília
Não se trata de invenção
De quem não tem boa cachola
Ai, ai
Isso não se aprende na escola
Ai, não
Isso não se aprende na escola.
(Não se aprende na escola, Haroldo Barbosa, 1951)

Neste caso, o tom jocoso e malicioso da canção, sugerindo que outros interesses, menos patrióticos, teriam também participado da decisão do futuro imperador em permanecer no Brasil e que tais interesses não são ensinados, além de relativizar o peso dos heróis nacionais que encontraram na escola uma de suas principais instâncias de perpetuação, ironiza o próprio o conhecimento escolar na medida em que o acusa de incompletude e parcialidade. A letra da canção continua nessa toada zombeteira e "picante", sempre voltando a esse refrão que reforça o apartamento entre a escola e a experiência da vida, desta vez especificamente a partir do uso de tradicionais conteúdos escolares. 


\section{CONSIDERAC̣̃̃ES FINAIS: “CLAVES” DE INTERPRETAC̣ÃO}

Este artigo propôs uma análise de um recorte do processo de escolarização no Brasil, entre as décadas de 1930 e 1950, era de ouro do rádio, tomando a canção popular como fonte e objeto de pesquisa, ancorando-se teoricamente no diálogo com a história social. Neste sentido, vale observar que E. P. Thompson fez da literatura uma de suas fontes mais importantes, elemento de sua escrita historiográfica e recurso metodológico por meio do qual buscou aproximar-se das sensações, afetos cotidianos, questões morais, enfim, toda essa matéria encarnada em ideias e sentimentos nos homens e mulheres trabalhadores, às voltas com os processos de industrialização, que estudou. Comprometida com a promoção da emoção mais que com o registro stricto sensu, a fonte literária permite alcançar essa miríade de experiências que nem sempre se apresentam em outros tipos de documentação. O mesmo parece ser válido para a música, feita para ser ouvida e para despertar no outro uma reação também emocional, o que constitui a peculiaridade destes tipos de registros históricos.

Os sambas aqui apresentados, ainda que de modo indireto, tratam de questões ligadas à escola, à instrução e ao analfabetismo, recortadas a partir do universo e das experiências dos trabalhadores pobres da cidade. Partem de situações e sujeitos particulares mas se constituem em exercícios sonoros de crítica social. Analisados em conjunto, permitem estabelecer algumas chaves de interpretação e tópicas mais constantes: a desigualdade das oportunidades escolares, a associação entre a educação formal e as elites culturais e econômicas, a dificuldade de acesso e permanência na escola por parte da população trabalhadora, a oposição entre a oralidade - da qual se nutrem os sambas - e a escrita e, por fim, uma tendência a certo anti-intelectualismo presente nos muitos momentos em que a "escola da vida" aparece como mais útil que a escola regular.

Em "Educação e Experiência", Thompson afirmou que o anti-intelectualismo foi uma das reações dos trabalhadores frente à "marcha do intelecto" que, a partir da década de 1790, representou para este grupo, acima de tudo, controle social e negação da própria experiência (THOMPSON, 2002, p. 32); mostrou, acompanhando a literatura romântica inglesa, como se produziu, ao longo do século XIX, um antagonismo entre o intelecto - escolar, racional, frio, pertencente ao universo da educação formal - e o sentimento - mais forte para aqueles que traziam apenas os aprendizados da vida. Talvez não seja inadequado considerar aqui uma hipótese tangente a esta. Guardadas 
as diferenças de tempos, espaços e sujeitos, muitos sambas escritos e cantados por estes artistas que se autodenominavam malandros trazem um desdém quanto aos saberes e sujeitos escolarizados, valorizando antes, em linguagem própria, carregada de emoção, a experiência prática da vida, os saberes efetivados na labuta cotidiana e na pobreza. Minha proposição é a de que esta é uma forma de crítica social e resistência, fundamentada na valorização de si, na denúncia da desigualdade e das precárias condições de vida que ela impõe aos pobres e, especialmente, uma crítica à visão da escola como caminho de ascensão social e cultural. Alguns dos sambas trabalhados neste texto assinalam a falácia da ideia da transformação social via educação; apontam para o diálogo difícil entre a cultura escolar e as culturas dos alunos que tem no preconceito linguístico uma de suas facetas mais evidentes; denunciam o fracasso de um projeto político e cultural que conta com "a educação por sua capacidade universalmente reconhecida de socializar indivíduos nos valores que as sociedades, através de seus segmentos organizados, querem ver internalizados" (BOMENY, 1999, p.139). O uso recorrente do humor e da ironia como elementos semânticos pode ser compreendido como recurso crítico em conteúdo e forma, capaz de relativizar regras sociais rígidas por meio do deboche (BREMMER, ROODENBURG, 2000).

Em perspectiva diacrônica, os problemas colocados por esses sambas malandros sobre a escola e a educação persistem em intensidade e urgência. No entanto, como alertava Thompson (2002), é preciso acautelar-se frente ao risco de uma visão romântica desse processo cujas consequências podem ser a ampliação das desvantagens e desigualdades educacionais e o aprofundamento do que Libâneo (2012) nomeia como "dualismo perverso da educação brasileira". Esta visão romântica pode dar origem a uma postura complacente em relação ao aprendizado daqueles que a escola tende a considerar "carentes"; pode promover e justificar a definição de conteúdos mínimos necessários e suficientes para o ingresso no mundo do trabalho; noutras palavras, muitos "Bastiões".

\section{REFERÊNCIAS}

ALZUGUIR. R. Wilson Baptista, o samba foi sua glória. Rio de Janeiro: Casa da Palavra, 2013.

AZEVEDO, R. Abençoado \& danado do samba, um estudo sobre o discurso popular. São Paulo: Edusp, 2013.

BAKHTIN, M. Cultura popular na idade média e no renascimento: o contexto de François Rabelais. São Paulo: Hucitec, 1987. 
BERTUCCI, L. M., FARIA FILHO, L. M., OLIVEIRA, M. A. T. Edward P. Thompson, história e formação. Belo Horizonte: Editora UFMG, 2010.

BOMENY, M. B. H. Três decretos e um ministério: a propósito da educação no Estado Novo. In: PANDOLFI, D. (org.). Repensando o Estado Novo. Rio de Janeiro: Ed. Fundação Getúlio Vargas, p. 137-166, 1999.

BOTO, C. Rousseau preceptor: orientações pedagógicas para a instrução de crianças verdadeiras. Cadernos de Pesquisa, São Paulo, v. 42, n. 145, p. 226-247, Apr. 2012.

BRASIL. Decreto N. 7.566, 23 de setembro de 1909. Cria nas capitais dos Estados da Escolas de Aprendizes Artífices, para o ensino profissional primário e gratuito. Rio de Janeiro, 23 de setembro de 1909. Disponível em: < http://portal.mec.gov.br/setec/arquivos/pdf3/ decreto_7566_1909.pdf>. Acesso em: 18 mai. 2018.

BREMMER, J., ROODENBURG, H. Introdução: humor e história. In: BREMMER, J., ROODENBURG, H. (org.). Uma história cultural do humor. Rio de Janeiro: Record, p. 13-25, 2000.

BRITO, I. M. Samba na Cidade de São Paulo (1900-1930). São Paulo: Edusp, Série Antropologia, n 14, 1986.

CÂNDIDO, A. A literatura e formação do homem. In: DANTAS, V. (org.). Textos de Intervenção. São Paulo: Duas Cidades / Editora 34, 2002, p. 77-92.

COELHO, P. Educadores do rádio: concepções, realizações e recepção de programas educacionais radiofônicos (1935-1950). Rio de Janeiro: Maud, 2017.

CONTIER, A. D. Música no Brasil: história e interdisciplinaridade. Algumas interpretações (1926-1980). In: SIMPÓSIO NACIONAL DE HISTÓRIA, 16., 1991, Rio de Janeiro. História em debate: problemas, temas e perspectivas. Anais do XVI Simpósio da Associação Nacional dos Professores Universitários de História. [S.1.]: CNPQ/InFour, p. 151-189.

CONTIER, A. D. Passarinhada do Brasil: canto orfeônico, educação e getulismo. Bauru, SP: EDUSC, 1998.

CUNHA, M. C. P. “Não tá sopa”: Sambas e sambistas no Rio de Janeiro, de 1890 a 1930. Campinas, SP: Editora Unicamp, 2015.

ESPERIDIÃO, N. Educação musical e formação de professores: suíte e variações sobre o tema [online]. São Paulo: Globus Editora, 2012.

GILLIOLI, R. de S. P. Educação e Cultura no rádio brasileiro: concepção de rádioescola em Roquette Pinto. 2008. Tese (Doutorado em Educação) - Faculdade de Educação, Universidade de São Paulo, São Paulo.

GOMES, B. F. Wilson Batista e sua época. Rio de Janeiro: Funarte, 1985.

HOBSBAWM, E. J. História Social do Jazz. 2a ed. Rio de Janeiro: Paz e Terra, 1990.

INSTITUTO CULTURAL CRAVO ALBIN. Dicionário Cravo Albin da música popular brasileira. Verbete Geraldo Pereira. < http://dicionariompb.com.br/geraldo-pereira>. Acesso em: 23 abri. 2018. 
JOST, M. A construção/invenção do samba: mediação e interação estratégica. Revista do Instituto de Estudos Brasileiros, Brasil, n. 62, p. 112-125, dez. 2015.

LIBÂNEO, J. C. O dualismo perverso da escola pública brasileira: escola do conhecimento para os ricos, escola do acolhimento social para os pobres. Educação e Pesquisa, São Paulo, v. 38, n. 1, p. 13-28, 2012.

MENEZES, J. E. de O. Rádio e cidade, vínculos sonoros. São Paulo: AnnaBlume, 2007.

MONTEIRO, A. N., SOUZA, R. F. de. Educação Musical e Nacionalismo: a história do canto orfeônico no ensino secundário brasileiro (1930-1960). História da Educação, ASPHE/FAE/UFPEL, Pelotas (13): 115-137, abril 2003.

MORAES, J. G. V. de. História e música: canção popular e conhecimento histórico. Revista Brasileira de História, São Paulo, v. 20, n. 39, p. 203-221, 2000.

NAPOLITANO, M. História e Música Popular: um mapa de leituras e questões. Revista de História, n. 157, p. 153-171, $2^{\circ}$ semestre, 2007.

NAPOLITANO, M. MPB: a trilha sonora da abertura política (1975-1982). Estudos Avançados, n. 24 (69), p. 389-402, 2010.

NAVES, S. C. A canção brasileira. Rio de Janeiro: Zahar, 2015.

QUEIROZ, L. R.. Música na escola: aspectos históricos da legislação nacional e perspectivas atuais a partir da Lei 11.769/2008. Revista da ABEM, Londrina, v. 20, n. 29, p. 23-38, jul. - dez. 2012.

ROCHA, F. Adoniran Barbosa, o poeta da cidade. Cotia, SP: Ateliê Editorial, 2002.

SALVADORI, M. A. B. Capoeiras e Malandros: Pedaços de uma sonora tradição popular (1890-1950). 1990. 2v. Dissertação (Mestrado em História) - Universidade Estadual de Campinas, Instituto de Filosofia e Ciências Humanas, Campinas, SP, 1990.

SALVADORI, M. A. B. Repercussões satíricas dos processos de escolarização do social nas ondas do rádio (1930-1940). Pro-Posições, Campinas, v. 23, n. 3, p. 195-212, dec. 2012.

SALVADORI, M. A. B. Sonoras cenas escolares: histórias sobre educação, rádio e humor. Revista Brasileira de História da Educação, Campinas, n. 24, p. 167-191, set./dez. 2010.

SCHUELER, A. F. M. Educação, experiência e emancipação: contribuições de E. P. Thompson para a história da educação. Trabalho necessário, Rio de Janeiro, ano 12, n. 18, p. 1-25, 2014.

SILVA, J. L. de O. A. da. Rádio: oralidade mediatizada. São Paulo: AnnaBlume, 1999.

THOMPSON, E. P. Tempo, disciplina de trabalho e capitalismo industrial. In: THOMPSON, E. P. Costumes em comum. São Paulo: Companhia das Letras, p. 267-304, 1998.

THOMPSON, E. P. Educação e experiência. In: THOMPSON, E. P. Os Românticos. Rio de Janeiro: Civilização Brasileira, p. 11-48, 2002.

VIDAL, D. G., BICCAS, M. de S. As múltiplas estratégias de escolarização do social em São Paulo (1770-1970): Cultura e práticas escolares. In: VIDAL, D. G. (org.). Educação e reforma: 
o Rio de Janeiro nos anos 1920-1930. Belo Horizonte: Argumentum, São Paulo: CNPq: USP, Núcleo Interdisciplinar de Estudos e Pesquisas em História da Educação, p. 19-44, 2008.

WISNIK, J. M. O som e o sentido, uma outra história das músicas. São Paulo: Companhia das Letras, 1989.

\section{DISCOGRAFIA}

LP Aracy de Almeida, Continental, 16.411-A, 1951.

LP Histórias das Malocas, Chantcler, s/d.

\section{NOTAS}

${ }^{1}$ O programa foi lançado em 1955. Este e outros trechos podem ser ouvidos no LP História das Malocas. São Paulo, Chantcler, s./d.

${ }^{2}$ Acompanhando os debates sobre radiodifusão nos anos 1930, observa-se que não havia consenso entre o uso educativo do rádio e seu uso mais diretamente comercial e voltado ao lazer. A defesa dessas diferentes posições pode ser analisada, por exemplo, por meio de periódicos que traziam notícias sobre a programação e cartas de radiouvintes. Ver (SALVADORI, 2012).

${ }^{3}$ As referências ao samba como "ritmo primitivo" ou "ritmo bárbaro" eram muito frequentes na imprensa. Na revista Carioca, semanário publicado a partir de 1935, por exemplo, eram comuns as cartas de ouvintes queixosos da proliferação de sambas populares distantes em ritmo, melodia e letra dos nobres ideais aos quais a verdadeira arte, supostamente, deveria se devotar. Na revista Cultura Política, ligada ao Departamento de Imprensa e Propaganda, veiculada entre 1941 e 1945, a mesma crítica se fazia presente (SALVADORI, 2010).

${ }^{4}$ LP Histórias das Malocas, Chantcler, s/d.

${ }^{5}$ LP Aracy de Almeida, Continental, 16.411-A, 1951.

Submetido: $24 / 05 / 2018$

Aprovado: 07/08/2018

Contato:

Faculdade de Educação da Universidade de São Paulo Avenida da Universidade, n. 308, Cidade Universitária

São Paulo $\mid$ UF $\mid$ Brasil

CEP 05.508-040 